\title{
Can Follicular Fluid Anti-Mullerian Hormone Level Be a Determinant of Pregnancy in Women Under 35 Years of Age?
}

\author{
Turabi Yilmaz ${ }^{1}$, Safak Tavukcuoglu$^{1}$, Seval Tasdemir ${ }^{1}$, Semra Esenkaya $^{1}$, Tülay İrez ${ }^{2}$
}

\begin{abstract}
Objectives: The failure of oocyte morphological assessment to predict in vitro fertilization (IVF) outcome has led the researchers to examine biochemical criteria of follicular fluid (FF). Anti-Mullerian hormone (AMH), an important marker of ovarian reserve, is secreted by the granulosa cells. The aim of this study is to investigate the relationship between the FF (AMH) levels and oocyte, embryo quality, fertilization, and clinical pregnancy.

Materials and Methods: The FF (AMH) levels of 61 patients (mean age: $33.72 \pm 4.82$ years; range: 21 to 42 years) were analyzed. The $\mathrm{FF}(\mathrm{AMH})$ levels were measured by the quantitative auto-analyzer with an electro-chemiluminescence assay.

Results: The FF $(\mathrm{AMH})$ levels in patients under 35 years of age were higher in pregnant women than non-pregnant ones $(\mathrm{P}<0.01)$. Conclusion: Our study results showed that the $\mathrm{FF}(\mathrm{AMH})$ levels were correlated with the quality of oocyte and embryo and were the predictors of clinical pregnancy in patients younger than 35 years of age.

Keywords: Anti-Mullerian hormone, Clinical pregnancy, Embryo, Follicular Fluid, In vitro fertilization, Oocyte
\end{abstract}

\section{Introduction}

Oocyte quality is one of the major factors affecting success in in-vitro fertilization (IVF)/intracytoplasmic sperm injection (ICSI) applications. Several studies have shown that the morphological studies are insufficient to determine the oocyte quality $(1,2)$. Therefore, some researchers have addressed biochemical markers to predict the oocyte quality, secretion of cumulus corona, and granulosa cells surrounding the oocyte in the developmental stages of the follicle (3-5).

The follicular fluid (FF) micro-environment is critical in terms of the cytoplasmic and nucleus maturation of the oocyte $(6,7)$. With the recent studies, it has been understood that anti-Mullerian hormone $(\mathrm{AMH})$ related to the development of ovarian follicle is a candidate molecule to be used in ovarian follicle reserve (3). $\mathrm{AMH}$ also known as Mullerian-inhibiting substance is a main regulator in the follicle development $(8,9)$.

Several studies have been carried out to predict the status of the ovaries with quantitative measurements of AMH. In classic IVF application, serum baseline AMH levels were shown to be associated with follicle count, fertilization rate, and female age-related results (10). Many studies have demonstrated that baseline AMH levels decrease proportionally with the age of the woman, indicating a positive correlation with the follicle count $(11,12)$. The
AMH levels between 1.66 and $4.52 \mathrm{ng} / \mathrm{mL}$ indicate goodquality oocytes which are produced with morphologically superior embryos of these oocytes (13). Some authors reported predictive results of pregnancy related to FF (AMH) levels, whereas some others showed controversial results $(14,15)$. In a very few numbers of studies, the level of the AMH level in the FF has been shown to reflect the oocyte quality (16).

Due to limited number of studies on FF (AMH) levels, in the present study we aimed to investigate whether FF (AMH) concentrations have any effect on the oocyte count and quality, ICSI fertilization rate, development, and quality of the embryo and also whether the age has any effect on the rate of clinical pregnancy.

\section{Materials and Methods \\ The study was carried out at Ferti-jin In-Vitro Fertilization Center. The oocytes were isolated from FF when the follicular size was about $\geq 15 \mathrm{~mm}$ in diameter with the help of sterile injectors. The remaining FF was centrifuged at $1800 \mathrm{rpm}(300 \mathrm{~g})$ for 15 minutes. Two milliliters from the supernatant were stored in liquid nitrogen tank to be studied later. The AMH levels of the collected samples were studied using an AMH kit with Roche Cobas e601 auto-analyzer (Roche Diagnostics, USA) by electro- chemiluminescence immune-assay (ECLIA) (17,18).}

Received 10 February 2017, Accepted 23 August 2017, Available online 12 September 2017

${ }^{1}$ Ferti-Jin In Vitro Fertilization Center, Istanbul, Turkey. ${ }^{2}$ Department of Histology and Embryology, Medical Faculty, Biruni University, Istanbul, Turkey

*Corresponding Author: Tülay İrez, Tel:+90 532244 6039, E-mail: tirez@biruni.edu.tr 
The FF samples from 5 patients were evaluated by both enzyme-linked immunosorbent assay (ELISA) and ECLIA for control (19). The obtained results were consistent in both tests (Table 1).

Table 2 shows demographic and clinical characteristics of patients.

The Roche branded AMH kit and the Roche Cobas e601 auto-analyser ECLIA were used to evaluate the AMH levels of FF in 61 patients in 4 groups. These groups are as following: (1) Very low level AMH group, $\leq 1.0 \mathrm{ng} / \mathrm{mL}$; (2) Low level AMH group, 1.0-2.1 ng/mL; (3) Moderate level AMH group, 2.1-3.6 ng/mL; (4) High level AMH group, $>3.6 \mathrm{ng} / \mathrm{mL}$ (Table 3 ).

For fertilization, metaphase II (MII) oocytes were taken into consideration for statistical analysis and the developing embryos were investigated in terms of blastomere number (According to Baczkowski et al's criteria), the percentage of fragmentation, and their size (whether they were of equal size) (20).

Semen Analysis and Preparation of Sperm

Sperm analysis was carried out as per the World Health Organization (WHO) criteria (21).

\section{ICSI Procedure}

The sperm prepared by using the Narishige micromanipulator was injected into the oocytes MII stage. To check for fertilization of oocytes (eggs), the fertilized oocytes were observed 16-20 hours after ICSI for the presence of two round nuclear structures, the male and female pronuclei (PN), formed by the sperm and egg.

Assessment of the Embryo

The morphology of the embryo was assessed using Alpha, ESHRE, ASRM consensus measures.

\section{Statistical Analysis}

Statistical analysis was performed using SPSS version 22.0 software (IBM Corporation, Armonk, NY, USA). Descriptive data were expressed in mean, standard deviation, and frequency. The Shapiro-Wilks test was used to analyze normally distributed variables. Moreover, Mann Whitney $U$ test was used for the comparison of quantitative data and the comparisons between 2 groups who do not have normally distributed parameters. Oneway Analysis of Variance (ANOVA) test was used for the comparisons between groups with normally distributed parameters and differences between groups were examined by Tamhane T2 test. Furthermore, Kruskal-Wallis test was used for the comparisons between the groups whose parameters were not normally distributed and Mann Whitney $U$ test was used for detection of the group causing difference. In addition, chi-square test, continuity (Yates) correction test, and Fisher exact test were used for the comparison of qualitative data. Significance was assessed at $P<0.05$ level.
Table 1. AMH Levels of FF Samples from 5 Patients on Beckman Gen II and Roche

\begin{tabular}{lcc}
\hline & Beckman Gen II $(\mathrm{ng} / \mathrm{mL})$ & Roche $(\mathrm{ng} / \mathrm{mL})$ \\
\hline Sample AMH $(\mathrm{ng} / \mathrm{mL})$ & Elisa & Eclia \\
1 & 1.73 & 1.90 \\
2 & 0.91 & 1.13 \\
3 & 0.5 & 0.59 \\
4 & 14.3 & 15.1 \\
5 & 5.93 & 6.11 \\
\hline
\end{tabular}

Table 2. Demographic and Clinical Characteristics of Patients

\begin{tabular}{lcc}
\hline & Min-Max & Mean \pm SD \\
\hline Age (y) & $21-42$ & $33.72 \pm 4.82$ \\
AMH $(\mathrm{ng} / \mathrm{mL})$ & $0.26-14.05$ & $2.14 \pm 2.24$ \\
$\mathrm{BMI}\left(\mathrm{kg} / \mathrm{m}^{2}\right)$ & $19.5-29.8$ & $24.1 \pm 1.8$ \\
No. of oocyte & $1-27$ & $10.05 \pm 6.66$ \\
M I & $0-8$ & $1.69 \pm 1.52$ \\
M II & $2-21$ & $698 \pm 4.84$ \\
No. of fertilization & $1-13$ & $4.61 \pm 3.58$ \\
Fertilization (\%) & $1-100$ & $67.16 \pm 28.54$ \\
No. of embryo & $1-13$ & $3.84 \pm 3.08$ \\
No. of good quality day 2 embryo & $1-10$ & $3.54 \pm 2.68$ \\
No. of poor quality embryos & $0-4$ & $08 \pm .14$ \\
No. of good quality day 3 embryo & $0-10$ & $3.05 \pm 2.53$ \\
Sperm count (million) & $1-200$ & $35.49 \pm 39.01$ \\
Motility (\%) & $0-80$ & $46.39 \pm 19.22$ \\
Morphology (\%) & $1-10$ & $6 \pm 2.18$ \\
Thickness of endometrium (mm) & $6.25-15.47$ & $9.61 \pm 2.12$ \\
Dose(IU) & $150-600$ & $373.77 \pm 129.54$ \\
\hline
\end{tabular}

\section{Results}

No statistically significant difference was observed among AMH groups in terms of fertilization percentages $(P>0.05)$. The rate of pregnancy was found to be lower in the group with very low level of AMH (14.3\%) than the groups with moderate level of AMH (53.8\%) $(P=0.022)$ and high level of AMH (54.5\%) $(P=0.035)(P<0.05)$. There was also no significant difference among other groups $(P>0.05)$.

However, there was a statistically significant correlation $(P=0.001, P<0.01, P=0.044, P<0.05)$ in the positive direction and at the levels of $51.5 \%$ and $32.1 \%$ between the oocyte counts and AMH levels of women aged under and 35 years and over (Figures 1 and 2). There was no statistically significant difference in pregnancy rate among the group of women who were under and over 35 years of age $(P>0.05)$ as per the induction of drug dose protocol.

In patients who were under 35 years of age, the area under the ROC curve for the AMH level was 0.771 and the standard error was 0.082 , which was significantly higher than $0.5(P=0.006, P<0.05)$. In patients who were over 35 years of age, the area under the ROC curve for AMH level was found to be 0.558 and the standard error was 0.124 , which was not significantly higher than 0.5 $(P=0.670, P>0.05)$. For the AMH test, the cut-off point in pregnant women under 35 years of age was 1.72. Of this value, the sensitivity, the specificity, and the positive 
Table 3. Evaluation of Characteristics of Women According to AMH Groups

\begin{tabular}{|c|c|c|c|c|c|}
\hline AMH Levels & $\begin{array}{c}<1 \mathrm{ng}<\mathrm{mL} \\
\text { Mean } \pm \text { SD } \\
\text { Median }\end{array}$ & $\begin{array}{c}1.1-2 \mathrm{ng} / \mathrm{mL} \\
\text { Mean } \pm S D \\
\text { Median }\end{array}$ & $\begin{array}{c}2.1-3.6 \mathrm{ng} / \mathrm{mL} \\
\text { Mean } \pm S D \\
\text { Median }\end{array}$ & $\begin{array}{c}>3.6 \mathrm{ng} / \mathrm{mL} \\
\text { Mean } \pm \text { SD } \\
\text { Median }\end{array}$ & $P$ \\
\hline Number of patients & 17 & 25 & 11 & 8 & \\
\hline Age $(y)$ & $35.53 \pm 4.35$ & $33.76 \pm 3.8$ & $32.45 \pm 4.41$ & $31.5 \pm 7.89$ & $0183^{a}$ \\
\hline No. of oocytes & $5.88 \pm 4.43(5)$ & $10.28 \pm 6.35$ (10) & $11.82 \pm 6.68$ (14) & $15.75 \pm 6.98(16.5)$ & $0.006^{b, d}$ \\
\hline MII oocytes & $3.94 \pm 2.79(3)$ & $6.92 \pm 4.17(7)$ & $7.82 \pm 4.62(9)$ & $12.5 \pm 5.83(13.5)$ & $0.002^{b, d}$ \\
\hline$\%$ Fertilization & $62 \pm 22.84(66)$ & $72.56 \pm 28.24(75)$ & $65.45 \pm 39.04(77)$ & $63.63 \pm 26.32(61.5)$ & $0.483^{b}$ \\
\hline No. of good quality embryos 3rd day & $1.47 \pm 0.51(1)$ & $3.08 \pm 2.04(3)$ & $3.55 \pm 2.84(2)$ & $5.63 \pm 3.78(6)$ & $0.011^{b, c}$ \\
\hline Dose of FSH IU & $480.88 \pm 99.42(450)$ & $348 \pm 118.35(300)$ & $354.55 \pm 111.7(300)$ & $253.13 \pm 89.08(225)$ & $0.001^{b, d}$ \\
\hline
\end{tabular}

Abbreviations: AMH, Anti-Mullerian hormone; MII, Metaphase II.

a One-way ANOVA test; ${ }^{\mathrm{b}}$ Kruskall-Wallis test; ${ }^{\mathrm{c}} P<0.05$; ${ }^{\mathrm{d}} P<0.01$.

predictive values were $0.75,0.78$, and 0.70 , respectively. Moreover, the negative predictive value was found to be 0.77 (Figure 3).

The cut-off point for the patients who were over 35 years of age could not be determined, since the area under ROC curve for AMH was not significantly higher than 0.5.

\section{Discussion}

The results of our study were similar to the positive correlation between FF (AMH) level and the quality of oocyte and embryo as shown in the study by Kim et al (22). In the study by Irez et al in 2011, the relationship between FF (AMH) level and the quality of oocyte and embryo was reported (23). In the studies conducted by Ebner et al (24), Irez et al (23), and Kim et al (22) in the years of 2006, 2011, and 2014, they found that FF (AMH) levels were directly correlated with oocyte quality. This piece of finding was in line with the previous studies on AMH.

The FF (AMH) and oocyte fertilization success were evaluated as a very good predictor of IVF application in the retrospective study by Takahashi et al (25). In this study, it was understood that FF (AMH) level did not show a significant relationship with ICSI fertilization.

Investigators showed that FF (AMH) levels were useful markers for embryo implantation; however, they could not find a significant difference in follicles producing high and low AMH in terms of oocyte and embryo quality (10). On the other hand, Cupisti et al (3) and Mehta et al (26) demonstrated an inverse relation of FF (AMH) level with potential fertilization in oocyte maturation and growth, oocyte quality, and pregnancy rate. In the present study, the AMH levels were measured in all of the follicles with a diameter $\geq 15 \mathrm{~mm}$, rather than specific follicle. Through measurements, we observed that the specific follicles which contained oocytes were not affected by the other follicular micro environment.

In this study clinical pregnancy rates were found to be (statistically) significantly high when the FF (AMH) levels were higher than $2.1 \mathrm{ng} / \mathrm{mL}$ (Table 4). The FF (AMH) levels were found to have a predictive effect on pregnancy

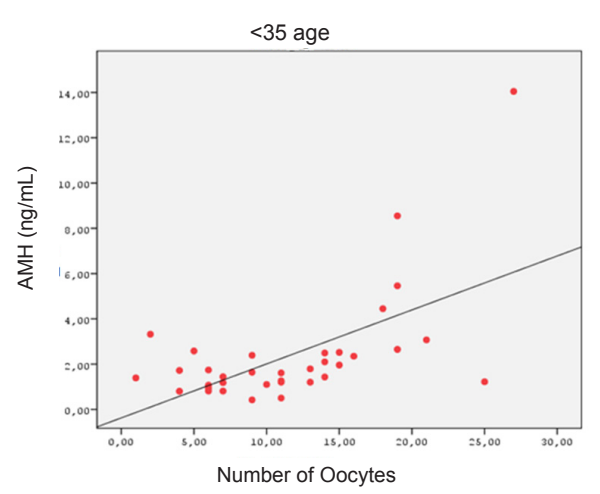

Figure 1. Correlation Between the FF AMH Levels $(\mathrm{ng} / \mathrm{mL})$ and the Number of Oocytes Under the Age of $35(r=0.515, P<0.01)$.

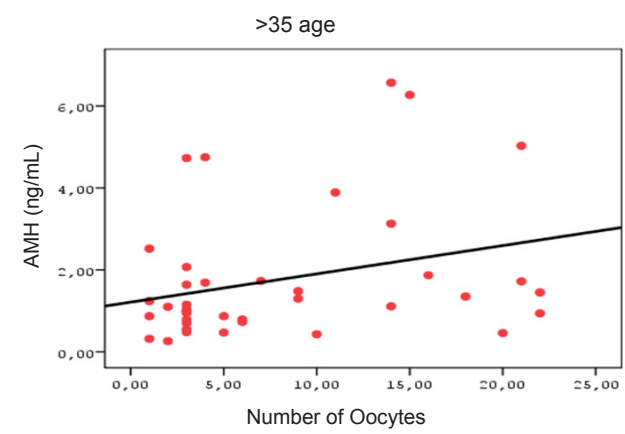

Figure 2. Distribution of the Number of Oocytes and FF AMH Levels $(\mathrm{ng} / \mathrm{mL})$ in Women Over 35 Years of Age $(r=0.321, P<0.044)$.

in women under 35 years of age, compared to the women over 35 years of age.

Nonetheless, this study suffers from some limitations. First, only the FF samples taken from the follicles $\geq 15 \mathrm{~mm}$ were included in the study, and the MII oocytes obtained from these follicles were fertilized by ICSI. However, the sperm samples obtained via TESA or micro-TESE in the patients with the diagnosis of azoospermia and patients with polycystic ovary syndrome were excluded, which in turn limited the sample size of this study. Second, due to the high cost, we were unable to carry out molecular analyses. Third, only women within the age range of 21 
Table 4. Pregnancy Rates in AMH Groups

\begin{tabular}{|c|c|c|c|c|c|}
\hline \multirow[b]{2}{*}{ Pregnancy } & \multicolumn{4}{|c|}{ AMH } & \multirow[b]{2}{*}{$P$} \\
\hline & $\begin{array}{c}<1 \mathrm{ng} / \mathrm{mL} \\
\text { No. (\%) }\end{array}$ & $\begin{array}{c}1.1-2 \mathrm{ng} / \mathrm{mL} \\
\text { No. (\%) }\end{array}$ & $\begin{array}{c}2.1-3.6 \mathrm{ng} / \mathrm{mL} \\
\text { No. (\%) }\end{array}$ & $\begin{array}{c}>3.6 \mathrm{ng} / \mathrm{mL} \\
\text { No. (\%) }\end{array}$ & \\
\hline Positive & $3(17.6)$ & $8(32)$ & $6(54.5)$ & $5(62.5)$ & \multirow{2}{*}{$0.081^{\circ}$} \\
\hline Negative & $14(82.4)$ & $17(68)$ & $5(45.5)$ & $3(37.5)$ & \\
\hline
\end{tabular}

${ }^{\mathrm{a}}$ Chi-square test.
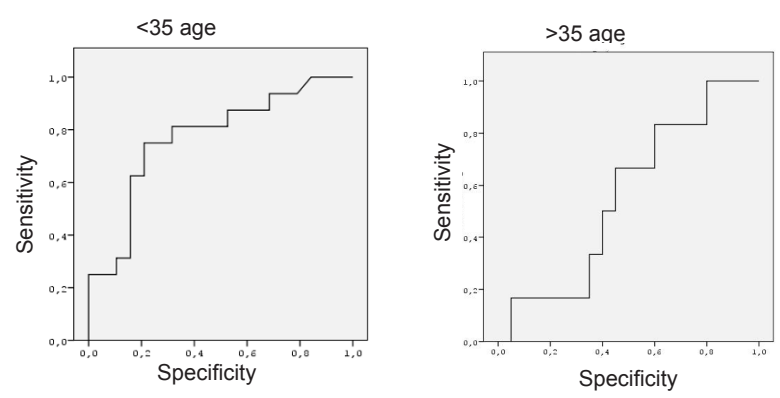

Figure 3. ROC Curve for Diagnosis of Pregnancy Under and Over the Age of 35 in the AMH Levels

to 42 years were included in this study, as the number of oocytes is reduced with increasing age.

In conclusion, the results of this study showed that the FF (AMH) levels were associated with oocyte and embryo quality and $\mathrm{FF}(\mathrm{AMH})$ levels were the predictors of clinical pregnancy in patients less than 35 years of age. However, further large-scale studies using molecular testing are needed to confirm these findings.

\section{Ethical Issues}

The study protocol was approved by the Zeynep Kamil Hospital Ethics Committee (No: 116, 2015).

\section{Conflict of Interests}

Authors declare that they have no conflict of interests.

\section{Financial Support}

The measurement of FF (AMH) levels performed by Duzen Laboratory Group, Ankara, Turkey, was funded by Yeni Yuzyil University, Faculty of Medicine, Istanbul, Turkey.

\section{Acknowledgments}

We would like to thank Duzen Laboratory Group, Ankara, Turkey for measuring FF (AMH) levels and Varyans Statistical Company for conducting the statistical analyses.

\section{References}

1. Lasiene K, Vitkus A, Valanciute A, Lasys V. Morphological criteria of oocyte quality. Medicina (Kaunas). 2009;45(7):509-515.

2. Kilani S, Cooke S, Tilia L, Chapman M. Does meiotic spindle normality predict improved blastocyst development, implantation and live birth rates? Fertil Steril. 2011;96(2):389-393. doi:10.1016/j.fertnstert.2011.05.023
3. Cupisti S, Dittrich R, Mueller A, et al. Correlations between anti-müllerian hormone, inhibin $\mathrm{B}$, and activin A in follicular fluid in IVF/ICSI patients for assessing the maturation and developmental potential of oocytes. Eur J Med Res. 2007;12(12):604-608.

4. Gilchrist RB, Lane M, Thompson JG. Oocyte-secreted factors: regulators of cumulus cell function and oocyte quality. Hum Reprod Update. 2008;14(2):159-177. doi:10.1093/humupd/dmm040

5. Revelli A, Delle Piane L, Casano S, Molinari E, Massobrio M, Rinaudo P. Follicular fluid content and oocyte quality: from single biochemical markers to metabolomics. Reprod Biol Endocrinol. 2009;7:40. doi:10.1186/1477-7827-7-40

6. Ola SI, Sun QY. Factors influencing the biochemical markers for predicting mammalian oocyte quality. J Reprod Dev. 2012;58(4):385-392. doi:10.1262/jrd.11-084H

7. de los Santos MJ, Garcia-Laez V, Beltran-Torregrosa D, et al. Hormonal and molecular characterization of follicular fluid, cumulus cells and oocytes from pre-ovulatory follicles in stimulated and unstimulated cycles. Hum Reprod. 2012;27(6):1596-1605. doi:10.1093/humrep/des082

8. Richardson SJ, Senikas V, Nelson JF. Follicular depletion during the menopausal transition: evidence for accelerated loss and ultimate exhaustion. J Clin Endocrinol Metab. 1987;65(6):1231-1237. doi:10.1210/jcem-65-6-1231

9. Faddy MJ, Gosden RG, Gougeon A, Richardson SJ, Nelson JF. Accelerated disappearance of ovarian follicles in midlife: implications for forecasting menopause. Hum Reprod. 1992;7(10):1342-1346.

10. Fanchin R, Mendez Lozano DH, Frydman N, et al. AntiMullerian hormone concentrations in the follicular fluid of the preovulatory follicle are predictive of the implantation potential of the ensuing embryo obtained by in vitro fertilization. J Clin Endocrinol Metab. 2007;92(5):17961802. doi:10.1210/jc.2006-1053

11. Jayaprakasan K, Campbell B, Hopkisson J, Johnson I, Raine-Fenning N. A prospective, comparative analysis of anti-Mullerian hormone, inhibin-B, and threedimensional ultrasound determinants of ovarian reserve in the prediction of poor response to controlled ovarian stimulation. Fertil Steril. 2010;93(3):855-864. doi:10.1016/j. fertnstert.2008.10.042

12. La Marca A, Sighinolfi G, Radi D, et al. Anti-Mullerian hormone $(\mathrm{AMH})$ as a predictive marker in assisted reproductive technology (ART). Hum Reprod Update. 2010;16(2):113-130. doi:10.1093/humupd/dmp036

13. Broekmans FJ, Faddy MJ, Scheffer G, te Velde ER. Antral follicle counts are related to age at natural fertility loss and age at menopause. Menopause. 2004;11(6 Pt 1):607-614. doi:10.1097/01.gme.0000123643.76105.27

14. Knight PG, Glister C. Local roles of TGF-beta superfamily members in the control of ovarian follicle development. 
Anim Reprod Sci. 2003;78(3-4):165-183. doi:10.1016/ S0378-4320(03)00089-7

15. Durlinger AL, Gruijters MJ, Kramer P, et al. Anti-Mullerian hormone inhibits initiation of primordial follicle growth in the mouse ovary. Endocrinology. 2002;143(3):1076-1084. doi:10.1210/endo.143.3.8691

16. Josso N, Racine C, di Clemente N, Rey R, Xavier F. The role of anti-Mullerian hormone in gonadal development. Mol Cell Endocrinol. 1998;145(1-2):3-7. doi:10.1016/S03037207(98)00186-5

17. Visser JA, Themmen AP. Anti-Mullerian hormone and folliculogenesis. Mol Cell Endocrinol. 2005;234(1-2):81-86. doi:10.1016/j.mce.2004.09.008

18. Marca AL, Volpe A. The Anti-Mullerian hormone and ovarian cancer. Hum Reprod Update. 2007;13(3):265-273. doi:10.1093/humupd/dml060

19. Anderson RA, Nelson SM, Wallace WH. Measuring anti-Mullerian hormone for the assessment of ovarian reserve: when and for whom is it indicated? Maturitas. 2012;71(1):28-33. doi:10.1016/j.maturitas.2011.11.008

20. Baczkowski T, Kurzawa R, Glabowski W. Methods of embryo scoring in in vitro fertilization. Reprod Biol. 2004;4(1):5-22.

21. WHO. WHO laboratory manual for the examination and processing of human semen. 5th ed. Geneva: WGO; 2010.

22. Kim JH, Lee JR, Chang HJ, Jee BC, Suh CS, Kim SH. Anti-
Mullerian hormone levels in the follicular fluid of the preovulatory follicle: a predictor for oocyte fertilization and quality of embryo. J Korean Med Sci. 2014;29(9):1266-1270. doi:10.3346/jkms.2014.29.9.1266

23. Irez T, Ocal P, Guralp O, Cetin M, Aydogan B, Sahmay S. Different serum anti-Mullerian hormone concentrations are associated with oocyte quality, embryo development parameters and IVF-ICSI outcomes. Arch Gynecol Obstet. 2011;284(5):1295-1301. doi:10.1007/s00404-011-1979-6

24. Ebner T, Sommergruber M, Moser M, Shebl O, SchreierLechner E, Tews G. Basal level of anti-Mullerian hormone is associated with oocyte quality in stimulated cycles. Hum Reprod. 2006;21(8):2022-2026. doi:10.1093/humrep/ del127

25. Takahashi C, Fujito A, Kazuka M, Sugiyama R, Ito H, Isaka K. Anti-Mullerian hormone substance from follicular fluid is positively associated with success in oocyte fertilization during in vitro fertilization. Fertil Steril. 2008;89(3):586591. doi:10.1016/j.fertnstert.2007.03.080

26. Mehta BN, Chimote MN, Chimote NN, Nath NM, Chimote NM. Follicular-fluid anti-Mullerian hormone (FF AMH) is a plausible biochemical indicator of functional viability of oocyte in conventional in vitro fertilization (IVF) cycles. J Hum Reprod Sci. 2013;6(2):99-105. doi:10.4103/09741208.117168

Copyright (c) 2018 The Author (s); This is an open-access article distributed under the terms of the Creative Commons Attribution License (http://creativecommons.org/licenses/by/4.0), which permits unrestricted use, distribution, and reproduction in any medium, provided the original work is properly cited. 